\title{
Modelling Pollutants Transport and Degradation through Wetlands
}

\author{
M.A. Imteaz ${ }^{a}$, V. Uddameri $^{\mathrm{b}}$ and A. Ahsan ${ }^{\mathrm{c}}$ \\ ${ }^{a}$ Faculty of Engineering and Industrial Sciences, Swinburne University of Technology, Melbourne, Australia. \\ ${ }^{b}$ Department of Civil and Environmental Engineering, Texas Tech University, Lubbock, Texas. \\ ${ }^{\mathrm{c}}$ Department of Civil Engineering, Faculty of Engineering, University Putra Malaysia, Selangor, Malaysia.
}

Email:mimteaz@swin.edu.au

\begin{abstract}
Wetlands play a number of roles in the water environment, principally water purification, flood control, and groundwater replenishment. In addition to these benefits, United Nations Millennium Ecosystem Assessment and Ramsar Convention defined wetlands to be of biosphere significance and societal importance in the areas of shoreline stabilisation, storm protection, cultural values, recreation and tourism, and climate change mitigation and adaptation. Wetlands are also considered the most biologically diverse of all ecosystems, serving as home to a wide range of plant and animal life. The function of most natural wetland systems is not to treat wastewater, however, their high potential for the filtering and the treatment of pollutants has been recognized by environmental scientists who specialize in the area of wastewater treatment.
\end{abstract}

In the past wetlands used to be in place naturally and used to provide ecological benefits to the mankind and environment. Through recognizing their immense benefits, human being started to construct artificial wetlands. Recently, constructed wetlands are recommended as one of the salient features of water sensitive urban design, which play an important role in water management and ecologically sustainable development. These constructed artificial wetland systems are highly controlled environments that intend to mimic the occurrences of soil, flora, and microorganisms in natural wetlands to help in treating wastewater effluent. Artificial wetlands provide the ability to experiment with flow regimes, micro-biotic composition, and flora in order to produce the most efficient treatment process.

Constructed wetlands are increasingly being designed and used to treat wastewaters. Majority of constructed wetlands are designed based on steady-state releases of pollutants loading. However, in some cases (i.e. aquaculture ponds) pollutant loadings are not steady-state, rather are intermittent. Pollutants transport analysis based on steady-state release (inflow) will be quite different from an analysis based on intermittent loading/inflow. In the past several studies were conducted on pollutants transport and degradation through wetlands using steady-state inflow of pollutants. In this paper, a simple numerical model is proposed and developed based on conservation of mass principle for the pollutants and transport through a wetland, considering a series of tanks. Tank-in-series approach assumes that the wetland is comprised of several interconnected tanks, each of which can be modeled as a continuous flow stirred tank reactor. As for pollutants, in this study organic matters are considered. Same numerical model can be used for different organic matters, considering different values of degradation rate. Using first-order kinetic equations of pollutants transport and degradation and applying Euler's method of difference equations a numerical model was developed. Developed numerical model can simulate pollutant transport and degradations for steadystate, continuous and/or irregular/intermittent pollutant loadings. Numerical model results were verified with earlier developed analytical solutions for intermittent pollutant loadings, which were applied for aquaculture ponds in Texas (USA). Numerical model results are close to the results derived from analytical solutions for the same condition. Reasons of some primary discrepancies are discussed. Developed numerical model was used to present different scenario using different flow rates, pond volumes and different masses of intermittent pollutants. It is found that all of these parameters have significant impact on outflow pollutants' concentrations.

Keywords: Intermittent loading, tanks-in-series, wetland, conservation of mass and pollutants 


\section{INTRODUCTION}

Constructed free surface water wetlands provide a better solution and cleaner option to treat wastewaters and are being used to treat municipal, industrial, and agricultural wastes (Behrends et al., 2001). Environmental concerns about meeting pollutant discharge targets have augmented the importance in using constructed wetlands for treating wastes from aquaculture facilities (Tilley et al., 2002). However, the utilization of this technology is viewed with skepticism by many watchdogs because of their variable influent quality. This variability is mainly resulted due to insufficient design protocols that do not totally catch the various hydrologic, chemical, and biological processes that the wetland is subject to (Persson \& Wittgren, 2003).

Wetlands in general have been modelled as plug flow reactors in which there is a continuous loading of the pollutant that goes through first-order removal under steady-state conditions. This approach, often referred to as the $\mathrm{k}-\mathrm{C}^{*}$ model, assumes steady and plug-flow conditions, and has been widely used, particularly in predicting water quality improvement in wastewater treatment wetlands. However, most wetlands do not behave as an ideal plug flow reactors but exhibit conditions of incomplete mixing due to tortuous flow paths caused by the presence of vegetation (Werner \& Kedlec, 2000). Plug-flow conditions rarely, if ever, occur in the field; some degree of dispersion and mixing usually occur. Departure from the assumed plug-flow conditions of the $\mathrm{k}-\mathrm{C}^{*}$ model is considered to be amongst the most significant factors influencing the accuracy of the model (Uddameri and Dyson, 2007). The $\mathrm{k}-\mathrm{C}^{*}$ model has been noted to be inadequate in many studies (Kadlec, 1999; Mankin \& Ikenberry, 2005). Hydrodynamic dispersion is the net result of variable advection and diffusion and can be rigorously modelled using plug flow with dispersion reactor models (Walker, 1998). Alternatively, a tanks-in-series approach can also be used and has been adopted by several researchers to characterize incomplete pollutant mixing in wetlands (Carleton, 2002; Kadlec \& Wallace, 2007; Wong \& Somes, 1995). This approach is intuitive and provides results comparable to a plug flow with dispersion model. Also, the mathematics is often easy to set up and solve, and as such, it is of considerable value in practical design applications.

The background or the initial concentration in the wetland is assumed to be constant in most first-order modelling efforts. In reality, the initial concentrations in the wetland may exhibit spatial variability. In many aquaculture facilities, the constructed wetland has to be developed with water from other sources because the wastewater discharges during the pre-harvest season are fairly minimal. The concentration of the pollutant in the water used to develop the wetland is sometimes noted to be greater than that in the wastewater released from the aquaculture ponds (Tilley et al., 2002). The performance of the wetland clearly depends upon its ability to assimilate both the effluent discharges as well as the pollutants present in the fill water. The effects of initial concentrations cannot be captured by steady-state models, and as such, a dynamic formulation is necessary for design of aquaculture treatment wetlands to capture unique field realities associated with such systems.

Some researchers have also used dynamic models (Imteaz \& Asaeda, 2000; Imteaz et al., 2003; Saloranta \& Anderson, 2007; Imteaz et al., 2009), which are warranted when seasonal variations in influent loadings are to be expected. This situation commonly arises when wetlands are used to treat wastes generated from cyclical or seasonal operations such as those encountered in aquaculture and storm water runoff treatment facilities.

As tank-in-series modelling approach is expected to be more accurate, especially with regard to situations where intermittent loadings are not completely stochastic but occur in some controlled fashion such as releases from aquaculture ponds. Uddameri (2010) has developed an analytical solution for pollutant removal and transport through a wetland under intermittent loadings using tank-in-series approach. This paper presents the development of a numerical model using tank-in-series approach. The model was developed using first-order kinetic equations of pollutants transport and degradation. Kinetic equations were deduced to numerical schemes applying Euler's method of difference equations. Numerical model results were verified with earlier developed analytical solutions for intermittent pollutant loadings, which were applied for aquaculture ponds in Texas (USA) under same loading conditions. Developed numerical model can simulate pollutant transport and degradations for steady-state, continuous and/or irregular/intermittent pollutant loadings. However, in this study the developed model was used only for intermittent loadings, as the analytical solutions were developed for intermittent loadings only and the objective of this study was to validate the developed numerical model. 


\section{NUMERICAL MODEL}

The tank-in-series approach assumes that the wetland is comprised of several interconnected tanks, each of which is modelled as a continuous flow stirred tank reactor. For the sake of illustration, assume a wetland is comprised of three such tanks. Using the conservation of mass principle, the governing equation for the transport of a pollutant in the first tank of the wetland can be written as follows:

$$
\frac{d C_{1}}{d t}+\left(\frac{Q}{V}+\lambda\right) * C_{1}=\frac{M}{V}
$$

Where $C_{1}$ is the concentration of the pollutant in the first-tank $\left(\mathrm{g} / \mathrm{m}^{3}\right)$; Q is the flowrate in the wetland $\left(\mathrm{m}^{3} / \mathrm{d}\right) ; \lambda$ is the first-order degradation rate of the pollutant $(1 / \mathrm{d})$; $\mathrm{V}$ is the volume of the tank $\left(\mathrm{m}^{3}\right)$ and $\mathrm{M}$ is the pollutant $(\mathrm{gm})$ inflow in the wetland within a certain time period (computational time step). The pollutant entering the tank 1 will undergo mixing and lateral displacement and enter the tank 2. Using Forward Difference Scheme, the above equation can be written in the following format for a time step of $\Delta \mathrm{t}$.

$$
C_{1,2}=\left[\frac{M}{V}-\left(\frac{Q}{V}+\lambda\right) * C_{1,1}\right] * \Delta t+C_{1,1}
$$

Where $C_{1,2}$ is the concentration of the pollutant in the Tank 1 after a certain time period $(\Delta t)$ and $C_{1,1}$ is the concentration of the pollutant in the Tank 1 at the beginning of the same time period.

The governing equation for the transport of a pollutant in the second tank of the wetland can be written as follows:

$$
\frac{d C_{2}}{d t}+\left(\frac{Q}{V}+\lambda\right) * C_{2}=\frac{Q}{V} C_{1,2}
$$

Where, $\mathrm{C}_{2}$ is the concentration of the pollutant in the Tank $2\left(\mathrm{~g} / \mathrm{m}^{3}\right)$. The pollutant exiting the tank $1\left(\mathrm{C}_{1,2}\right)$ is assumed to enter the tank 2. Using the same Forward Difference Scheme, the above equation can be written in the following format for a time step of $\Delta \mathrm{t}$.

$$
C_{2,2}=\left[\frac{Q}{V} C_{1,2}-\left(\frac{Q}{V}+\lambda\right) * C_{2,1}\right] * \Delta t+C_{2,1}
$$

Where $C_{2,2}$ is the concentration of the pollutant in the Tank 2 after a certain time period $(\Delta t)$ and $C_{2,1}$ is the concentration of the pollutant in the Tank 2 at the beginning of the same time period.

The governing equation for the transport of a pollutant in the third tank of the wetland can be written as follows:

$$
\frac{d C_{3}}{d t}+\left(\frac{Q}{V}+\lambda\right) * C_{3}=\frac{Q}{V} C_{2,2}
$$

Where, $\mathrm{C}_{3}$ is the concentration of the pollutant in the Tank $3\left(\mathrm{~g} / \mathrm{m}^{3}\right)$. The pollutant exiting the tank $2\left(\mathrm{C}_{2,2}\right)$ is assumed to enter the tank 3. Using the same Forward Difference Scheme, the above equation can be written in the following format for a time step of $\Delta \mathrm{t}$.

$$
C_{3,2}=\left[\frac{Q}{V} C_{2,2}-\left(\frac{Q}{V}+\lambda\right) * C_{3,1}\right] * \Delta t+C_{3,1}
$$


Where $\mathrm{C}_{3,2}$ is the concentration of the pollutant in the Tank 3 after a certain time period $(\Delta t)$ and $C_{3,1}$ is the concentration of the pollutant in the Tank 3 at the beginning of the same time period. Similarly, for $\mathrm{N}$ number of tanks in-series the above-equation can be generalised as:

$$
C_{N, 2}=\left[\frac{Q}{V} C_{N-1,2}-\left(\frac{Q}{V}+\lambda\right) * C_{N, 1}\right] * \Delta t+C_{N, 1}
$$

Above equations can be solved simultaneously to calculate pollutant concentrations at different locations (i.e. inflow, outflow and any other intermediate location depending on number of tanks considered) of the wetland at different time steps.

\section{MODEL RESULTS}

A numerical model was developed incorporating above-mentioned finite difference equations. The developed model was tested with the analytical solutions achieved by Uddameri (2010) for the similar conditions. Numerical model parameters were selected as per conditions/data provided in the solutions of Uddameri (2010). Following model conditions were selected for the simulations of the numerical model:

Wetland volume: $23,700 \mathrm{~m}^{3}$; Flowrate: 13,600 $\mathrm{m}^{3} /$ day; Degradation rate: 0.002 /day; Pollutant loadings: Three intermittent 1000 gm, each separated by 1.5 days and Computational time step: 0.25 day.

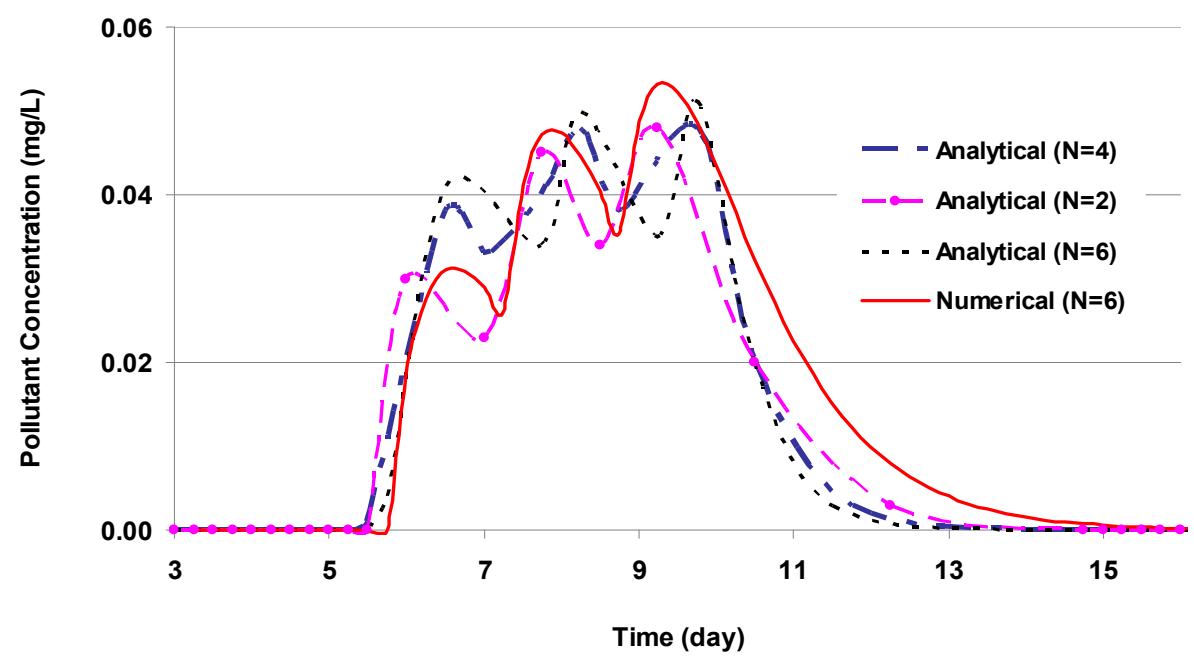

Figure 1. Comparison of numerical model $(\mathrm{N}=6)$ results with analytical solutions.

For the numerical model, it is considered that the pollutant loadings are applied/distributed within the period of computational time step. This computational time step may needs to be adjusted based on actual pollutant loading time. In reality a shorter time step may be required for a real instantaneous impulse loading. Model was simulated for a period of 17 days, covering three intermittent pollutant loading periods as well as decay of pollutant to a level of zero. Figure 1 shows the comparison of numerical model simulation $(\mathrm{N}=6)$ with Uddameri's analytical solutions (for $\mathrm{N}=2,4$ \& 6) for pollutant breakthrough curve near the inflow location of the wetland. It is obvious that pollutant breakthrough concentration with higher ' $N$ ' values will be higher, as the same mass of pollutant will be mixed with a smaller tank volume for higher ' $N$ ' values. It is found that with the addition of pollutant (1000 gm), the rise of concentration proceed rapidly. Both the models' results match for the rise of pollutant concentration in the wetland. However, it is found that maximum pollutant concentration following first pollutant loading is higher for the case of analytical solution. This discrepancy is due to the fact that in the analytical solution it was considered that the pollutant loading enters into the wetland within an infinitesimally small time period (i.e. impulse loading), which is supposed to create a higher pollutant concentration; whereas in numerical model it is considered that pollutant is entering within the specified computational time step (i.e. 0.25 day in this case). However, maximum pollutant concentrations following remaining two pollutant loadings through numerical solution closely match with the analytical solution. Numerical pollutant concentration peaks occur slightly prior to the analytical peaks, which might be due to the slight discrepancy in selecting proper time step. Selection of time step for the 
numerical computations is very important, especially for this case and computational time step should be at least equals to or a multiple of individual tank's residence time.

Developed model was used for different scenario presentations varying different model parameters. Figure 2 shows the effects of wetland volume on the pollutant concentrations near the outlet, keeping all other parameters same. It is found that with the increase in wetland volume, pollutant concentration near the outlet reduces significantly. Also, the pollutant curve gets flater (wider) and effect of intermittent loadings (three peaks) disappears. However, with the lower volume, the effect of intermittent loadings starts appearing with more than one peaks. In this case, first peak grows from day 3 to day 4, however before recession, again surpassed and starts growing by the effect of second loading. As such, only last two peaks look prominent. Figure 3 show the effects of magnitude of pollutant loadings (i.e. mass) on wetland pollutant concentrations keeping all other parameters same (Volume $=20,400 \mathrm{~m}^{3}, \mathrm{Q}=3400 \mathrm{~m}^{3} / \mathrm{d}$ ). Figures $3 \mathrm{a}$ and $3 \mathrm{~b}$ show the pollutant concentrations due to different masses $(500 \mathrm{~g}, 1000 \mathrm{~g}, 2000 \mathrm{~g}$ and $4000 \mathrm{~g})$ of intermittent pollutant loadings near the inflow and outflow of the wetland respectivly. In all the cases it is found that the effects of intermittent loadings disappear near the outlet. Figure 4 shows the effect of flowrate on wetland pollutant concentrations keeping all other parameters same. It is found that with the increase of flowrate, wetland pollutant concentration near the outlet can be reduced significantly, this is mainly due to the dilution effect of higher volume of inflows mixing with the same mass of pollutants. Also, with the lower flowrates, effects of intermittent loadings disappear.

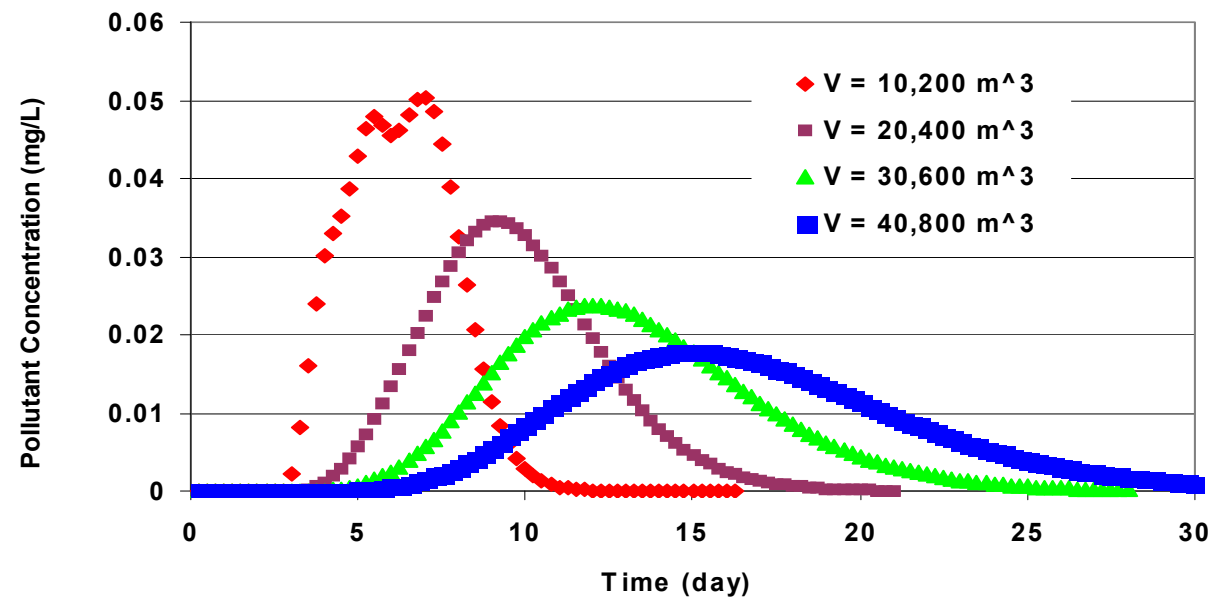

Figure 2. Effect of wetland volume on wetland pollutant reduction

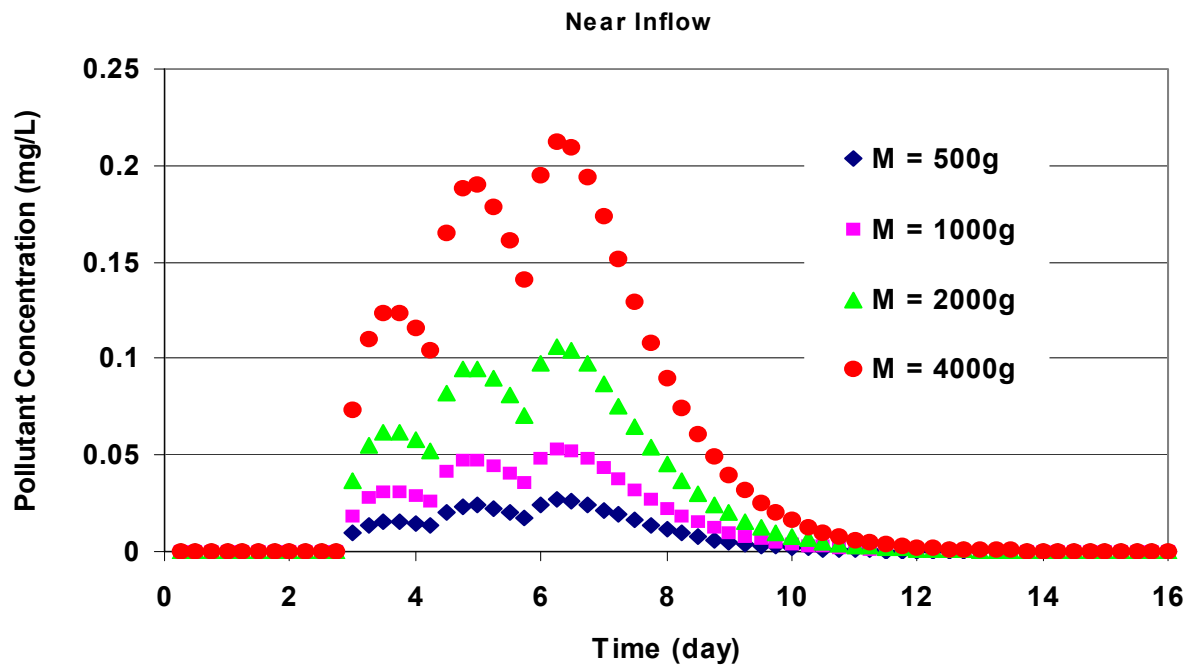

Figure 3a. Effect of inflow pollutant mass on wetland pollutant concentration (near the inlet) 


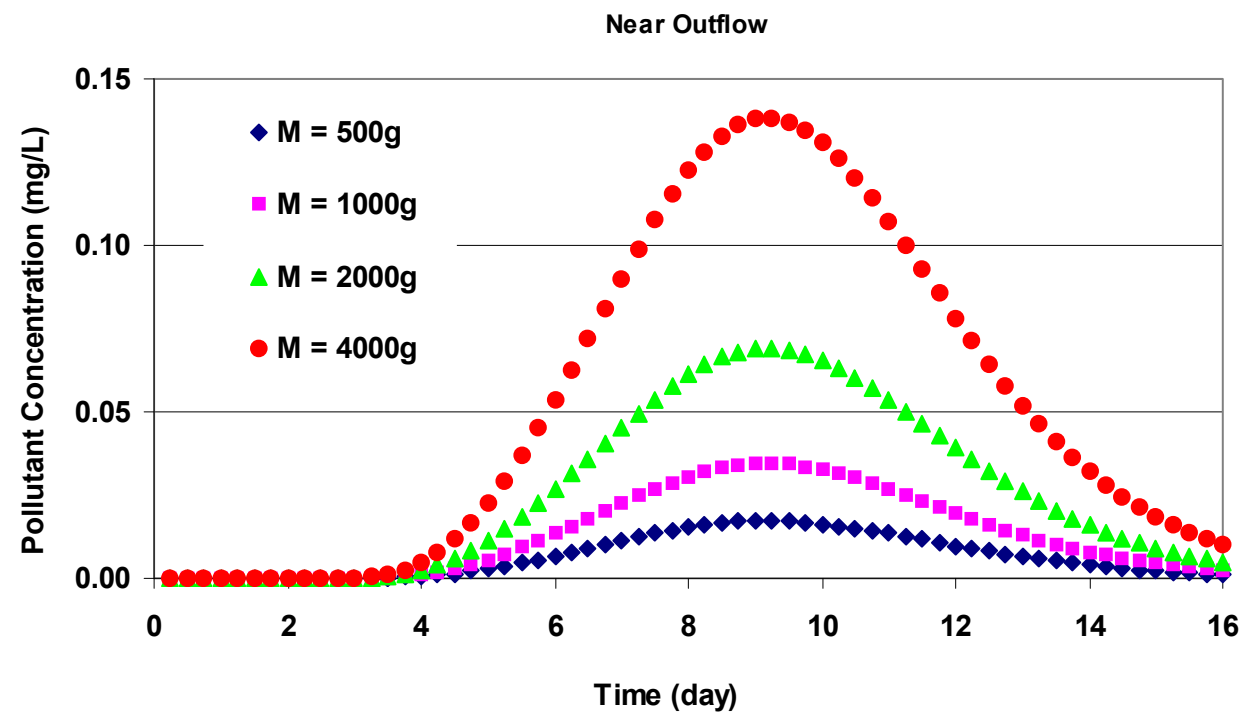

Figure 3b. Effect of inflow pollutant mass on wetland pollutant concentration (near the outlet)

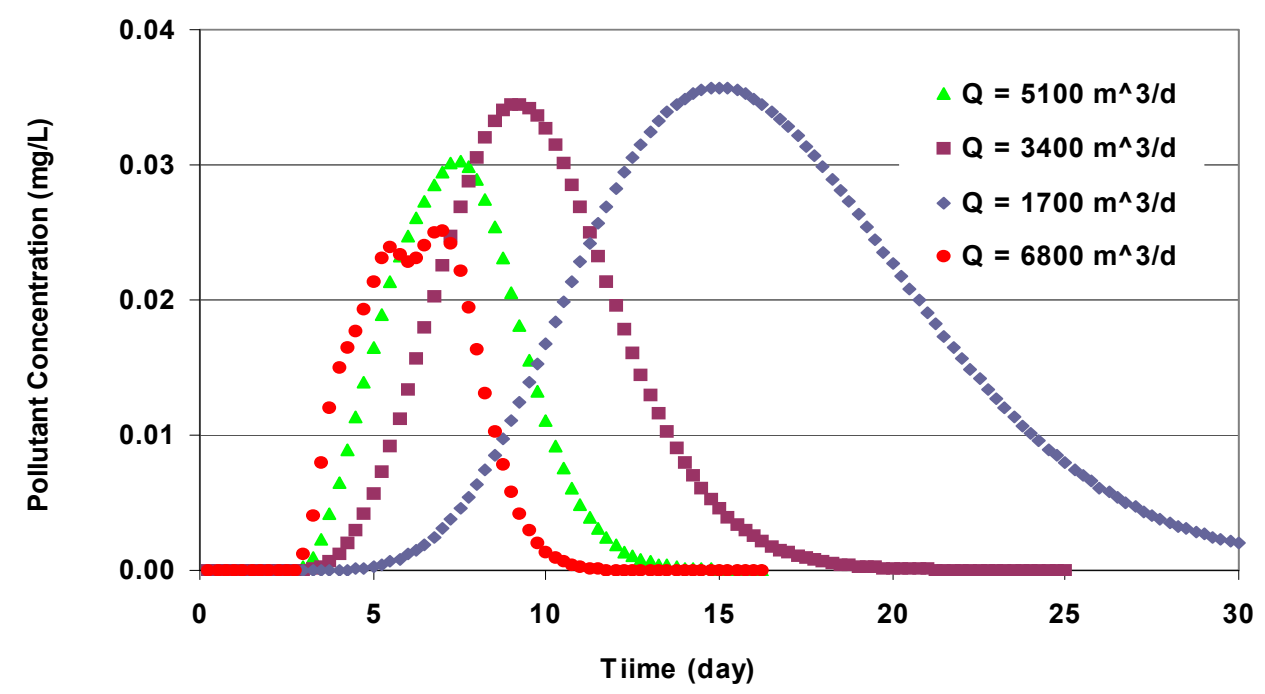

Figure 4. Effect of flowrate on wetland pollutant reduction

\section{DISCUSSION AND CONCLUSIONS}

A simple numerical model was developed to simulate pollutant degradation and transport through a wetland, considering the wetland as series of equal-sized tanks. In regards to the flow in the wetland, a steady-state condition was assumed, which implies that there is no net accumulation/storage of incoming wastewater and the inflow is equal to the outflow. However, the developed model can be modified to include unsteady flow conditions, incorporating increase/decrease of wetland net water storage. Numerical model results were compared with an earlier developed analytical solution for the same conditions and numerical results are in good agreement with the analytical solutions. Traditionally used $\mathrm{k}-\mathrm{C}^{*}$ model is not suitable for nonstochastically varying intermittent pollutant loadings, which is the case especially for aquaculture ponds. Developed numerical model can be used for any type of pollutant loadings (i.e. intermittent, continuous or stochastic). Developed model was used for several scenarios to assess the effects of other model parameters (i.e. wetland volume, mass of intermittent loadings and discharge). It was found that wetland volume has got much higher influence in reducing pollutant concentration compared to the discharge. For very large wetland volumes, inflows are not likely to be mixed totally, which is an assumption of tank-in-series approach. However, it is to be noted here 
that the volumes presented in this study are not the actual volumes needed to be mixed. Rather, total volume was sub-divided into six tanks, each of which is needed to be mixed. Model results in regards to pollutant breakthrough concentration near the inflow are highly dependent on number of assumed tanks (in series). However, after subsequent simulations for the following tanks, pollutant concentration near the outflow would be same.

Calibration is required for the determination of degradation rate for a particular type of pollutant or for particular wetlands. Mankin and Ikenberry (2005) evaluated a range of possible degradation rates. For the numerical model, selection of appropriate computational time step is an important task. It is recommended that time step should be selected in way that it matches with individual tank's retention/residence time, it should be at least equals to or an integer multiple of individual tank's residence time. Earlier developed analytical model was valid only for an instantaneous impulse loading, which occurs within an infinitesimal time. In reality, this time frame may not be infinitesimal and may vary. Advantage of the developed numerical model is that it can solve any type of pollutant loading having different spreading (breakthrough) time frames.

\section{REFERENCES}

Behrends, L., Houke, L., Bailey, E., Jansen, P. and Brown, D. (2001). Reciprocating constructed wetlands for treating industrial, municipal and agricultural wastewater. Water Science and Technology, 44, 399-405.

Carleton, J. (2002). Damkohler number distributions and constituent removal in treatment wetlands. Ecological Engineering, 19, 233-248. doi:10.1016/S0925-8574(02)00094-0.

Imteaz, M.A. and Asaeda, T. (2000) Artificial mixing of lake water by bubble plume and effects of bubbling operations on algal bloom, Water Research, 34(6), 1919-1929.

Imteaz, M.A., Asaeda, T. and Lockington, D. (2003). Modelling the effects of inflow parameters on lake water quality, Environmental Modeling \& Assessment, 8(2), 63-70.

Imteaz, M.A., Shanableh, A. and Asaeda, T. (2009). Modelling multi-species algal bloom in a lake and interalgal competitions, Water Science \& Technology, Vol. 60, No. 10, pp. 2599-2611.

Kadlec, R. H. (1999). The inadequacy of first order treatment wetland models. Ecological Engineering, 15, 105-120. doi:10.1016/S0925-8574(99)00039-7.

Kadlec, R. H. \& Wallace, S. D. (2007). Treatment wetlands (2nd ed.). Boca Raton, FL.: CRC.

Mankin, K. R. \& Ikenberry, C. D. (2005). Batch reactor unvegetated wetland performance in treating dairy wastewater. Journal of the American Water Resources Association, 40(6), 1527-1535. doi:10.1111/j.1752-1688.2004.tb01603.x.

Persson, S. F. \& Wittgren, H. (2003). How hydrologic and hydraulic conditions affect performance ponds. Ecological Engineering 21, 259-269. doi:10.1016/j.ecoleng.2003.12.004.

Saloranta, T. M. \& Anderson, T. (2007). MyLake-A multi-year lake simulation model code suitable for uncertainty and sensitivity analysis simulations, Ecological Modelling, 207(1), 45-60. doi: 10.1016/j.ecolmodel.2007.03.018

Tilley, D., Badrinarayanan, H., Rosati, R. \& Son, J. (2002). Constructed wetlands as recirculation filters in large-scale shrimp aquaculture. Aquacultural Engineering, 26, 81-109. doi:10.1016/S01448609(02)00010-9.

Uddameri, V. \& Dyson, B. (2007). A decision-analytic approach for designing aquaculture treatment wetlands subject to intermittent loading under uncertainty. Water, Air, and Soil Pollution, 186, 297-309. doi:10.1007/s11270-007-9486-x.

Uddameri, V. (2010). An analytical solution to model aquaculture wetlands subject to intermittent loading and variable initial concentrations. Environmental Modeling and Assessment, 15, 27-35. doi: 10.1007/s10666-009-9189-3.

Walker, D. J. (1998). Modelling residence time in stormwater ponds. Ecological Engineering, 10, $247-262$. doi:10.1016/S0925-8574(98)00016-0.

Werner, T. M., \& Kedlec, R. H. (2000). Wetland residence time distribution Modeling. Ecological Engineering, 15, 77-90. doi:10.1016/S0925-8574(99)00036-1.

Wong, T. H. F., \& Somes, N. L. G. (1995). A stochastic approach to designing wetlands for stormwater pollution control. Water Science and Technology, 32, 145-151. doi:10.1016/0273-1223(95)00549-3. 